\title{
PEMILIHAN LAYANAN SATUAN PENDIDIKAN SMP OLEH PELAJAR YANG BERDOMISILI DI KECAMATAN KURANJI KOTA PADANG
}

\author{
Fazil Akbari1, Yurni Suasti², Triyatno ${ }^{2}$ \\ Program Studi Pendidikan Geografi \\ Fakultas Ilmu Sosial, Universitas Negeri Padang \\ Email : Fazil.akbar13@gmail.com
}

\begin{abstract}
Abstrak
Tujuan penelitian ini untuk mendeskripsikan layanan satuan pendidikan SMP yang dipilih oleh pelajar yang berdomisili di Kecamatan Kuranji dan alasan pelajar di dalam memilih layanan satuan pendidikan SMP. Penelitian ini merupakan penelitian deskriptif dengan pendekatan kuantitatif. Populasi penelitian ini adalah pelajar SMP yang berdomisili di Kecamatan Kuranji yang berjumlah 8094 orang. Penarikan sampel menggunakan proportional random sampling dengan jumlah 98 orang. Data dikumpulkan melalui wawancara menggunakan kuesioner, kemudian dianalisis menggunakan teknik analisis deskriptif persentase. Penelitian ini menemukan bahwa layanan satuan pendidikan SMP yang dipilih oleh pelajar di Kecamatan Kuranji cenderung seimbang antara yang memilih layanan yang berada di dalam kecamatan dan berada di luar kecamatan, yakni 52 persen memilih layanan pendidikan yang berada di dalam Kecamatan Kuranji, sedangkan 48 persen memilih layanan pendidikan yang berada di luar Kecamatan Kuranji. Alasan pelajar memilih SMP yang berada di dalam kecamatan, sebagian besar memilih karena dekat dengan rumah. Untuk pelajar memilih SMP yang berada di luar kecamatan, sebagian besar memlih karena popularitas dan akreditasi sekolah tersebut, dan dorongan orangtua.
\end{abstract}

Kata kunci : Pemilihan Layanan, Satuan Pendidikan SMP, Pelajar SMP

\begin{abstract}
Aims of this research was to describe how junior high school of education unit service selected by students who are domiciled in Subdistrict Kuranji and reasons of students in choosing the education level of junior high school. This research is descriptive research with quantitative approach. The population of this research is the junior high school students residing in Kuranji district by the 8094 people, withdrawal of samples use a proportional random sampling and Slovin formula used in determining of samples with a total of 98 people. Data were collected through interviews using questionnaires, then a descriptive analysis techniques and using percentage. This research found that service units selected by the Junior High School education students at Kuranji Subdistrict tend to be balanced between the select service in the districts and are outside the district, namely, 52 percent chose education service located in Sub Kuranji, while 48 percent chose education service outside the Sub Kuranji. For the reasons students choose Junior High School in the district, the vast majority choose because it's near to home, since accreditation and facilities, as well as the encouragement of parents. For studentschoosing junior high school liesoutside the district, largely because of the popularity and achievements reasoned that school, because of school accreditation and motivation parents.
\end{abstract}

Keywords : Election Service, Junior High School Level Education Unit, Junior High Student

${ }^{1}$ Mahasiswa Program Studi Pendidikan Geografi ${ }^{2}$ Dosen Jurusan Geografi Fakultas Ilmu Sosial Universitas Negeri Padang, pembimbing 1; Dra. Yurni Suasti, M. Si, pembimbing 2 ; Triyatno, S. Pd, M. Si 


\section{PENDAHULUAN}

Pendidikan memiliki peranan yang sentral dalam pembangunan bangsa dan negara karena dari sanalah kecerdasan dan kemampuan serta watak bangsa di masa yang akan datang. Pendidikan mempunyai peran sebagai dasar dalam membentuk kualitas manusia yang mempunyai daya saing dan kemampuan dalam menyerap teknologi yang akan dapat meningkatkan produktivitas.

Undang-Undang Negara

Republik Indonesia nomor 20 tahun 2003 tentang Sistem Pendidikan Nasional Bab 2 tentang Dasar, Fungsi dan Tujuan Pendidikan Nasional Pasal 3 bahwa ;

"Pendidikan nasional berfungsi mengembangkan kemampuan dan membentuk watak serta peradaban bangsa yang bermartabat dalam rangka mencerdaskan kehidupan bangsa, bertujuan untuk berkembangnya potensi peserta didik agar menjadi manusia yang beriman dan bertakwa kepada Tuhan Yang Maha Esa, berakhlak mulia, sehat, berilmu, cakap, kreatif, mandiri, dan menjadi warga Negara yang demokratis serta bertanggung jawab".

Dalam upaya mencapai tujuan tersebut, setiap warga negara Indonesia berhak memperoleh pendidikan yang bermutu sesuai dengan minat dan bakat yang dimilikinya seperti yang diutarakan Maryati (2009) bahwa seseorang dapat memanfaatkan layanan pendidikan tanpa melihat pada status sosial, status ekonomi, suku, etnis, agama, dan gender.

Ketersediaan layanan satuan pendidikan SMP, Kota Padang khususnya di Kecamatan Kuranji terdapat SMP negeri 5 unit dan SMP Swasta sebanyak 6 unit (Kecamatan Kuranji Dalam Angka Tahun 2015), artinya bahwa banyak layanan yang bisa dipilih dan dimanfaatkan oleh pelajar untuk melanjutkan jenjang pendidikannya.

Istilah Layanan dalam Kamus Besar Bahasa Indonesia (KBBI) kata layanan berarti perihal cara melayani. Pelayanan pada dasarnya adalah kegiatan yang ditawarkan kepada konsumen atau pelanggan yang dilayani, yang bersifat tidak berwujud dan tidak dapat dimiliki. Pelayanan yang menjadi produk dari organisasi pemerintahan adalah pelayanan masyarakat (publik service). Pelayanan tersebut diberikan untuk memenuhi hak masyarakat, baik layanan sipil maupun publik.

Menurut Sulipan

layanan pendidikan dikategorikan dalam beberapa jenjang, salah satunya layanan sekolah kepada masyarakat dan siswa, meliputi : Informasi sekolah (program, peminatan, paket 
keahlian, pendaftaran dll) kepada masyarakat, pendaftaran dan penerimaan siswa baru, penyediaan ruang dan sarana belajar, pembelajaran yang sesuai dengan karakteristik siswa dan bimbingan belajar dan ekstrakurikuler.

Sekolah Menengah Pertama (SMP) dalam Peraturan Pemerintah No. 17 Tahun 2010 Tentang Pengelolaan dan Penyelenggaraan Pendidikan adalah salah satu bentuk satuan pendidikan formal yang menyelenggarakan pendidikan umum pada jenjang pendidikan dasar sebagai lanjutan dari SD, MI, atau bentuk lain yang sederajat atau lanjutan dari hasil belajar yang diakui sama atau setara SD atau MI.

Permendiknas Nomor 24 Tahun 2007 terkait Standar Sarana dan Prasarana Sekolah Menengah Pertama/Madrasah Tsanawiyah (SMP/MTS) Pasal 4 secara lebih luas yaitu, "Satu kelompok permukiman permanen dan terpencil dengan banyak penduduk lebih dari 1000 jiwa dilayani oleh satu SMP/MTs dalam jarak tempuh bagi peserta didik yang berjalan kaki maksimum 6 $\mathrm{km}$ melalui lintasan yang tidak membahayakan". Selain itu dalam peraturan tersebut juga dikatakan bahwa satu SMP minimal memiliki tiga rombongan belajar dan maksimal 24 rombongan belajar. Setiap SMP dengan tiga rombongan belajar mampu melayani 2000 jiwa, jika lebih dari 2000 jiwa perlu penambahan hingga maksimal 24 rombongan belajar.

Preferensi pelajar dalam memilih sekolah sangat bervariasi, karena setiap individu mempunyai keinginan berbeda-beda dalam memilih sekolah. Maryati (2009) dalam penelitiannya menemukan bahwa ada beberapa faktor yang mempengaruhi siswa dalam pemilihan sekolah faktor tersebut berupa kondisi sekolah, lokasi sekolah, dan faktor ekonomi. Dari 3 faktor tersebut, faktor yang paling besar pengaruhnya adalah kondisi dan lokasi sekolah. Sementara itu dalam penelitian Awang (2006) menyebutkan yang paling berpengaruh dalam memilih sekolah adalah faktor ketersediaan angkutan umum. Christaller (dalam Tarigan 2005) dalam teori Central Place pada tahun 1933 menjelaskan tentang distribusi spasial kota. Jika penduduk suatu wilayah pelayanan dengan satu pusat telah melebihi jarak terjauh dari tempat pusatnya akan melebihi jarak ekonominya, sehingga akan lebih efisien apabila mereka mencari pelayanan pada tempat pusat lainnya yang lebih dekat. Tamin (2000) mengatakan indikator aksesibilitas secara sederhana dapat dinyatakan dengan jarak. Jika suatu tempat berdekatan dengan tempat lainnya, dikatakan aksesibilitas antara kedua 
tempat tersebut tinggi. Sebaliknya jika berjauhan aksesibilitas antara keduanya rendah. Selain jarak dan waktu, biaya juga merupakan beberapa indikator aksesibilitas.

\section{METODE PENELITIAN}

\begin{tabular}{llr}
\multicolumn{2}{c}{ Penelitian ini } & merupakan \\
penelitian & deskriptif & dengan \\
pendekatan kuantitatif. & Populasi \\
penelitian ini & adalah seluruh Pelajar \\
SMP
\end{tabular}
SMP yang berdomisili di Kecamatan Kuranji dengan jumlah 8094 orang. Teknik penarikan sampel yang digunakan dalam penelitian yaitu teknik proportional random sampling, dan teknik penarikan jumlah sampel menggunakan rumus Slovin sehingga didapat jumlah sampel sebanyak 98 orang. Penelitian ini fokus pada satuan pendidikan yang dipilih oleh pelajar dan alasan pemilihan sekolah.

Penelitian menggunakan teknik observasi dan menggunakan kuisioner dalam pengumpulan data dan informasi. Sedangkan teknik analisis yang digunakan dalam penelitian ini adalah analisis deskriptif persentase.

\section{HASIL PENELITIAN DAN PEMBAHASAN}

Satuan Pendidikan SMP yang Dipilih oleh Pelajar

Penelitian ini menemukan, satuan pendidikan SMP yang dipilih oleh pelajar yang berdomisili di Kecamatan Kuranji dikelompokkan atas dua, yakni kelompok yang memilih satuan pendidikan SMP yang berada di dalam Kecamatan Kuranji dan yang memilih di luar Kecamatan Kuranji. Jumlah yang memilih satuan pendidikan SMP yang berada di dalam kecamatan dan luar kecamatan hampir berimbang, masing-masing adalah 52 persen memilih SMP yang berada di dalam Kecamatan Kuranji, dan 48 persen memilih SMP yang berada di luar Kecamatan Kuranji. Pada gambar 1, terlihat pada masing-masing kelurahan terlihat hasil yang cukup beragam antara yang memilih di dalam kecamatan dan memilih di luar kecamatan.

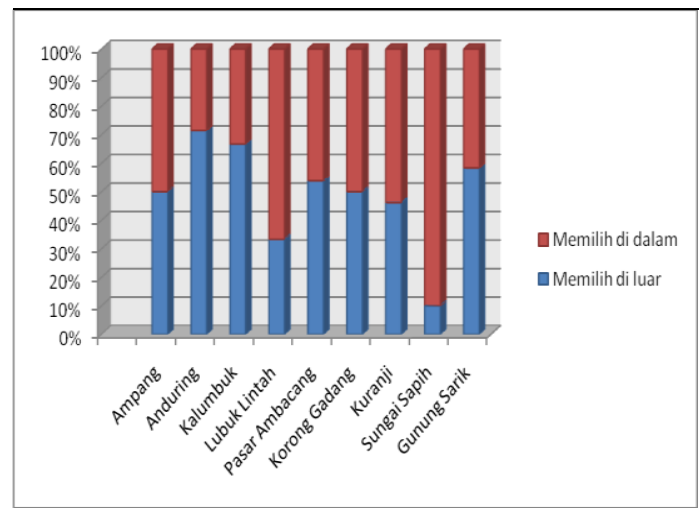

Gambar 1. Grafik Pilihan Pelajar yang Berdomisili di Kecamatan Kuranji 
Dari 9 kelurahan yang terdapat di Kecamatan Kuranji, siswa yang berdomisili di Kelurahan Sungai Sapih paling banyak memilih SMP di dalam kecamatan, dengan persentase sebesar 90 persen dari jumlah responden yang tinggal di Kelurahan Sungai Sapih.
Pada gambar 2 terkait satuan pendidikan SMP yang dipilih pelajar Sungai Sapih, SMP Negeri 18 merupakan satuan pendidikan yang paling banyak dipilih dengan 6 orang, lalu SMP Negeri 27 dengan 2 orang dan SMP Perti dengan 1 orang.

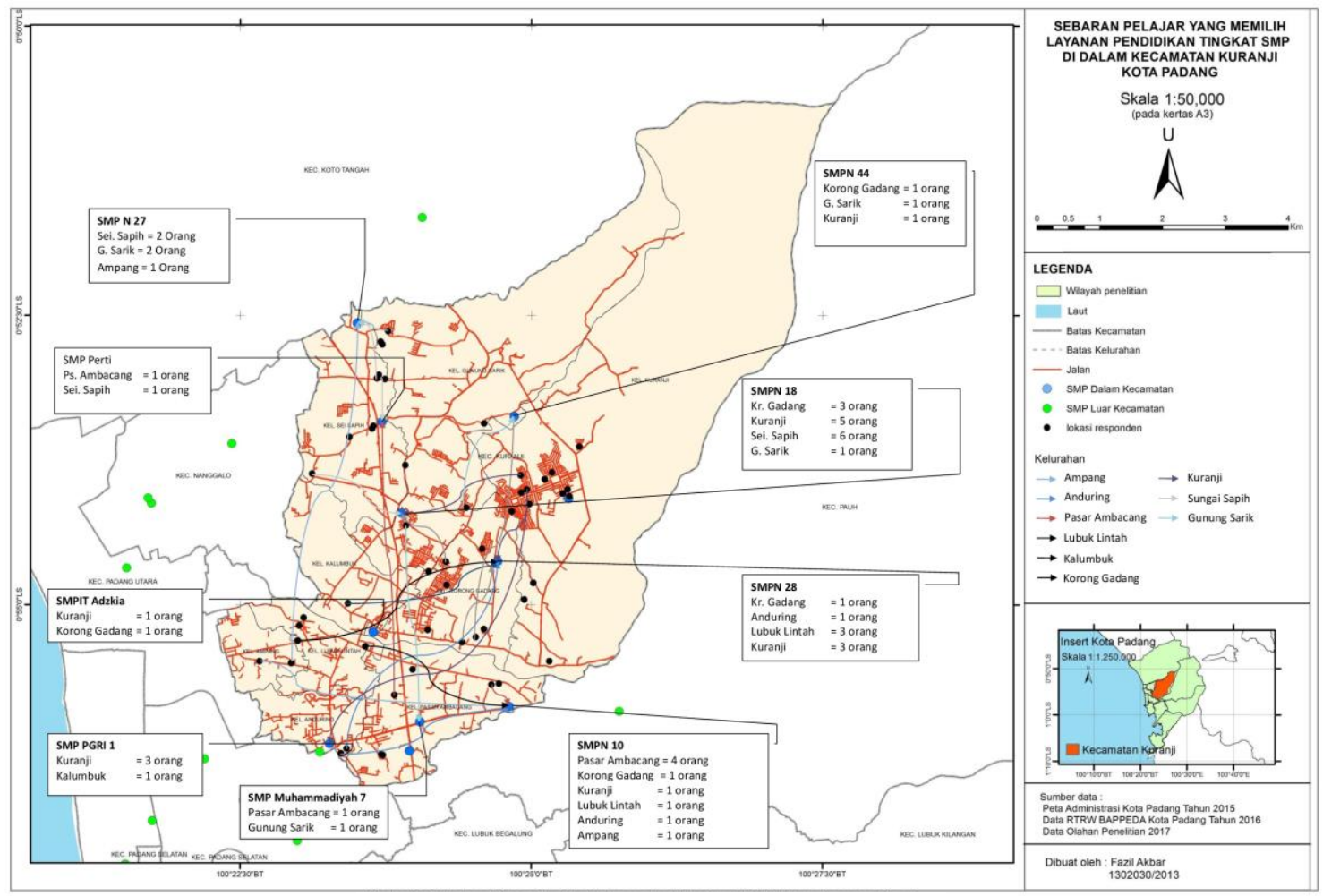

Gambar 2. Sebaran Pelajar yang Memilih SMP di Dalam Kecamatan Kuranji

Dari 9 kelurahan yang terdapat di Kecamatan Kuranji, ternyata 2 kelurahan lebih banyak memilih di luar kecamatan, yakni Kelurahan Anduring dan Kelurahan Kalumbuk. Siswa yang berdomisili di Kelurahan Ampang dan Kelurahan Kalumbuk sebagian besar memilih satuan pendidikan SMP di luar Kecamatan Kuranji, masing-masing adalah 70 persen pelajar Anduring dan 62 persen pelajar Kalumbuk memilih satuan pendidikan SMP yang berada di luar Kecamatan Kuranji. masing-masing SMP yang dipilih terdapat pada gambar 3. 


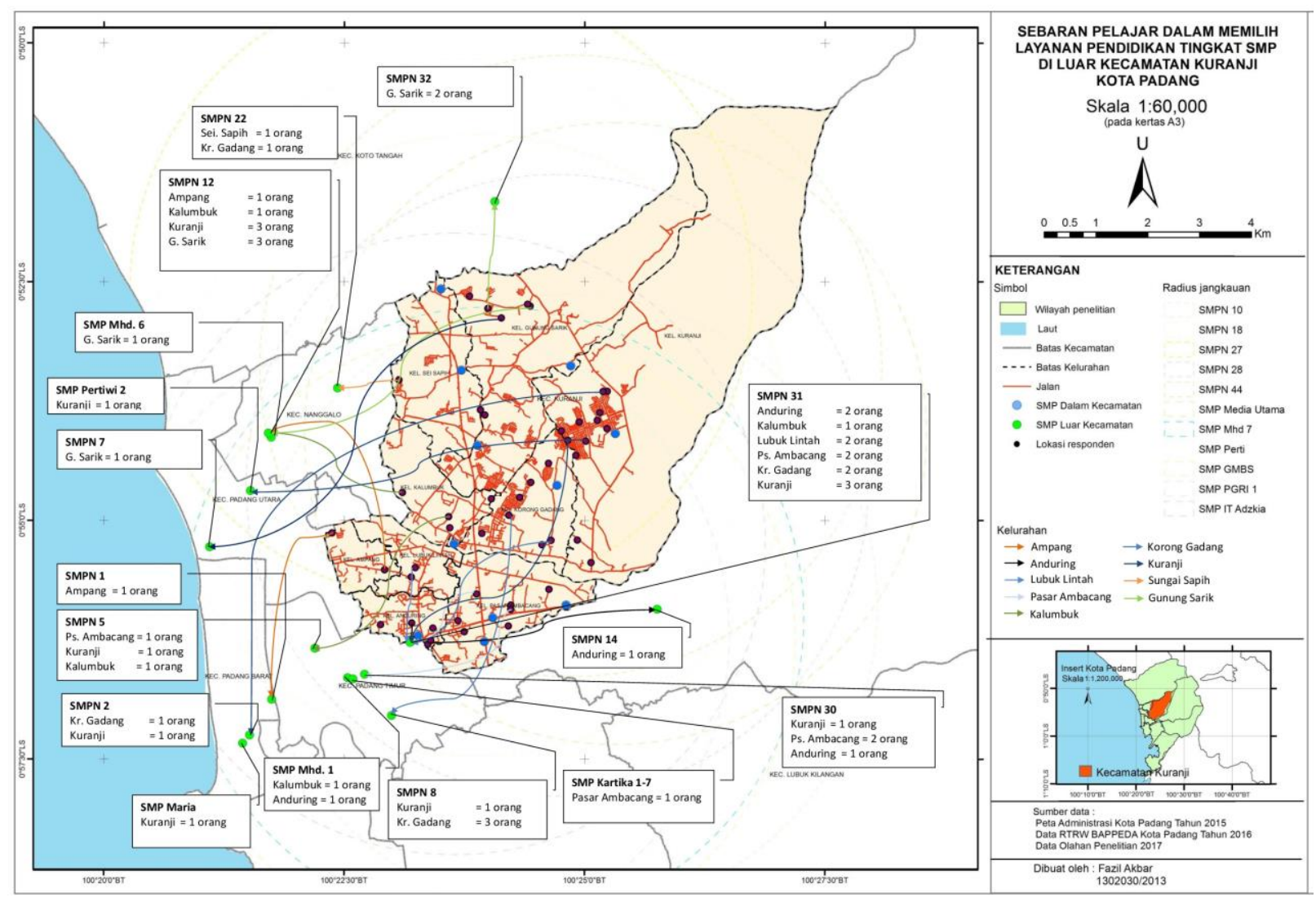

Gambar 3. Sebaran Pelajar yang Memilih SMP di Luar Kecamatan Kuranji

Satuan pendidikan SMP yang dipilih oleh pelajar yang berdomisili di Kelurahan Anduring, antara lain SMP Negeri 31 dengan 2 orang, SMP Negeri 14 dan SMP Negeri 30 masing-masing 1 orang. Kemudian untuk satuan pendidikan SMP yang dipilih pelajar yang berdomisili di Kelurahan Kalumbuk antara lain SMP Negeri 5, SMP Negeri 12 dan SMP Negeri 31 masing-masing 1 orang.

Dilihat dari segi NEM pelajar dan rayon sekolah, menunjukkan perbedaan antara yang memilih di dalam kecamatan dengan yang memilih di luar kecamatan.

Berdasarkan temuan bahwa pelajar yang memiliki NEM di atas 85 lebih banyak memilih layanan pendidikan tingkat SMP di luar Kecamatan Kuranji, dengan jumlah mencapai 59 persen dari total pelajar yang memilih di luar kecamatan seperti yang terdapat pada gambar 4, sedangkan yang memiliki NEM 60-85 dan <60 memiliki persentase lebih rendah dibanding dengan memiliki 
NEM >85 yang memilih di luar kecamatan.

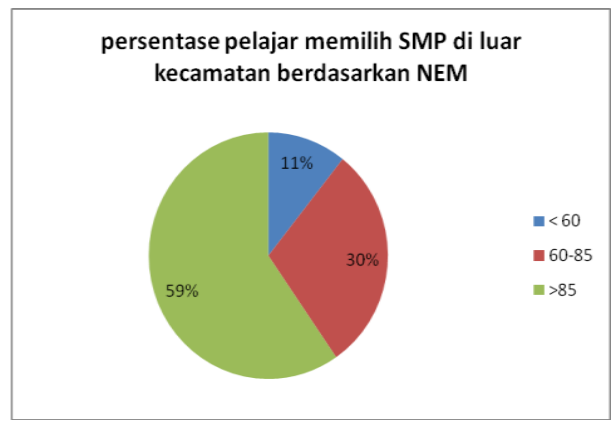

Gambar 4. Grafik memilih SMP luar kecamatan Berdasarkan NEM

Pelajar yang memiliki NEM 60-85 seperti yang terdapat pada gambar 5 bahwa lebih banyak memilih di dalam Kecamatan Kuranji dibandingkan dengan pelajar yang memiliki NEM $>85$ dan $\mathrm{NEM}<60$

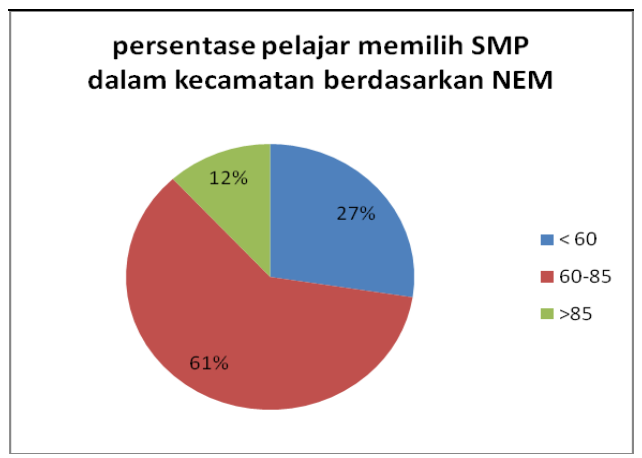

Gambar 5. Grafik Pelajar memilih SMP dalam Kecamatan Berdasarkan NEM

Ini menandakan bahwa mereka yang memiliki NEM tinggi punya keinginan untuk mendapatkan layanan pendidikan tingkat SMP yang lebih baik dari layanan pendidikan yang ada di dekat domisilinya. Ini terlihat di mana SMP di luar Kecamatan Kuranji yang dipilih pelajar merupakan SMP yang bisa dikatakan favorit dan unggul seperti SMPN 1, SMPN 2, SMPN 8 dan lain-lain.

Berdasarkan rayon sekolah, pada gambar 6 bahwa pelajar yang berdomisili di Kecamatan Kuranji lebih memilih satuan pendidikan SMP yang bukan rayon dari sekolah asal pelajar atau luar rayon sekolah sebelumnya, baik itu SMP yang berada di dalam Kecamatan Kuranji maupun yang berada di luar Kecamatan Kuranji.

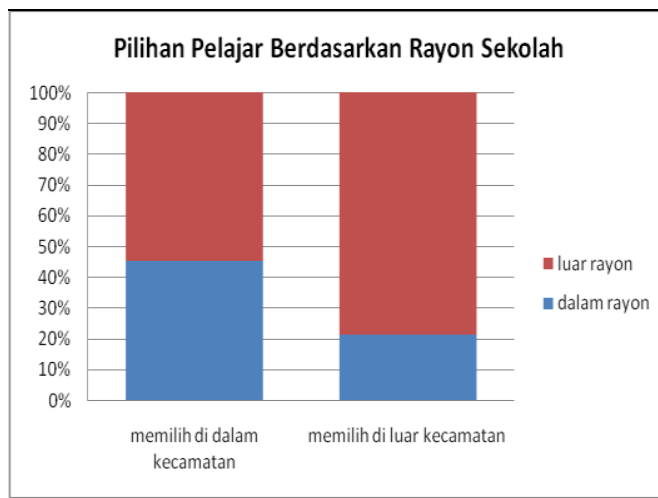

Gambar 6. Grafik Pilihan Pelajar Berdasarkan Rayon

Pelajar yang memilih layanan pendidikan SMP di dalam Kecamatan Kuranji terutama yang memilih layanan berstatus negeri cenderung mereka yang memiliki rayon sekolah di layanan tersebut. Pelajar yang memilih layanan pendidikan SMP di luar Kecamatan Kuranji mayoritas adalah layanan pendidikan SMP yang 
memang bukan rayon dari sekolah sebelumnya. yakni 80 persen dari pendidikan SMP yang di luar Kecamatan Kuranji.

\section{Alasan Pelajar Memilih Satuan Pendidikan SMP}

Penelitian ini menemukan 14 alasan pelajar dalam memilih satuan total pelajar memilih layanan pendidikan SMP. Beberapa alasan pelajar tersebut dikelompokkan antara yang memilih SMP di dalam Kecamatan Kuranji yang terdapat pada gambar 7 .

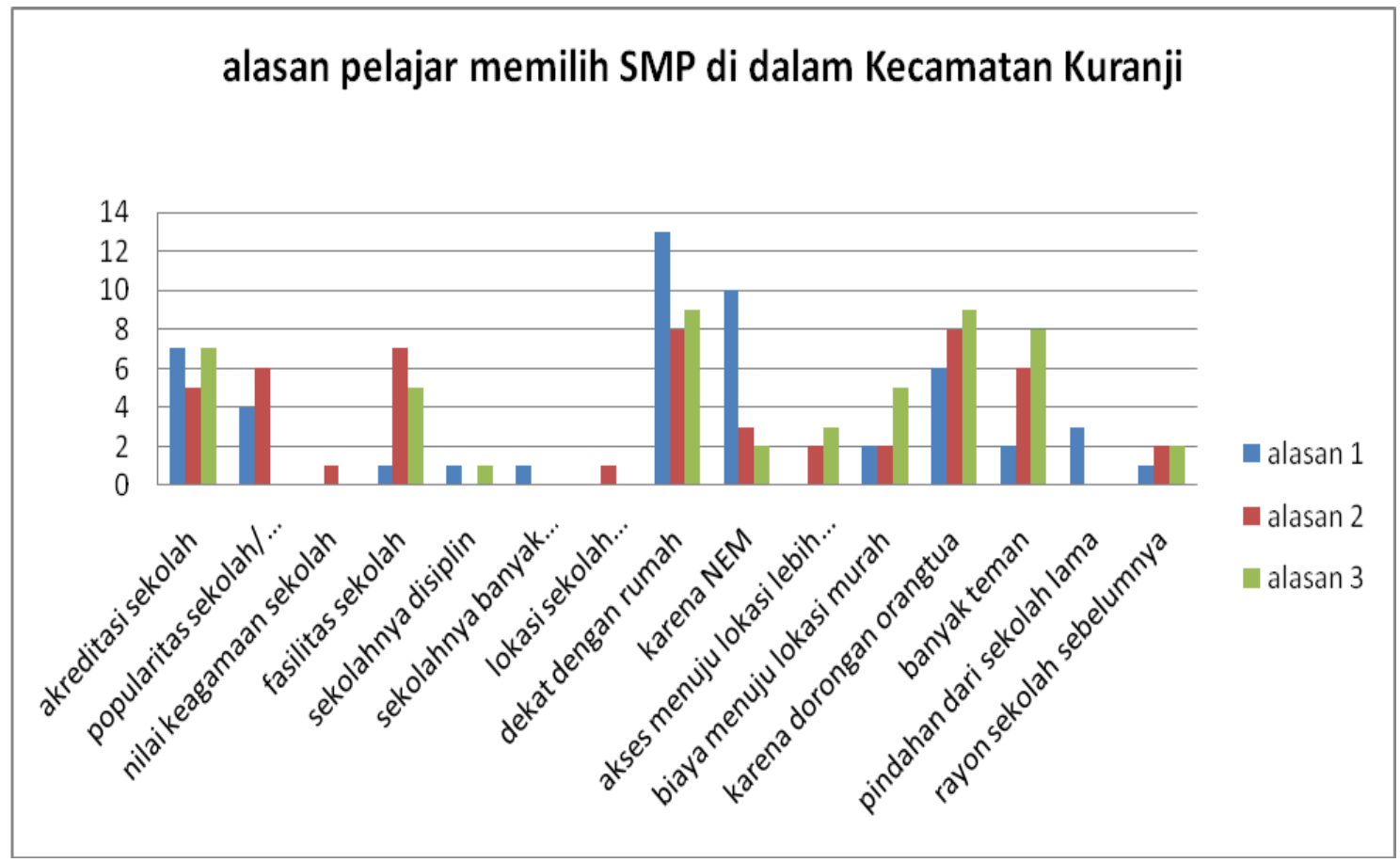

Gambar 7. Alasan pelajar memilih SMP di dalam Kecamatan Kuranji

Hasil temuan menunjukkan, alasan pelajar memilih SMP di dalam Kecamatan Kuranji sebagian besar beralasan karena dekat dengan rumah, kemudian alasan yang cukup banyak dikemukakan yaitu karena dorongan orangtua dan akreditasi sekolah dan fasilitas sekolah. Dari beberapa alasan yang disampaikan pelajar, faktor lokasi sekolah menjadi acuan pelajar dalam memilih sekolah. Kemudian pelajar juga memilih SMP berdasarkan kualitas dari sekolah tersebut, seperti terlihat pada gambar 7 bahwa sebagian besar pelajar memilih dengan alasan akreditasi dan fasilitas sekolah. Artinya bahwa pelajar SMP di Kecamatan Kuranji sudah 
mengetahui keunggulan dan kekurangan dari masing-masing SMP yang ada di Kecamatan Kuranji sebelum pelajar menetapkan pilihan untuk bersekolah di SMP yang ada di Kecamatan Kuranji. Selain itu bahwa peran dan dorongan dari orangtua juga menjadi alasan bagi pelajar dalam memilih SMP di Kecamatan Kuranji, artinya sebagian orangtua dari pelajar yang berdomisili di Kecamatan Kuranji mengarahkan anaknya dalam memilih sekolah yang lebih dekat dengan tempat tinggal mereka.

Pelajar yang memilih SMP di dalam Kecamatan Kuranji juga memiliki alasan yang beragam seperti yang terdapat pada gambar 8 .

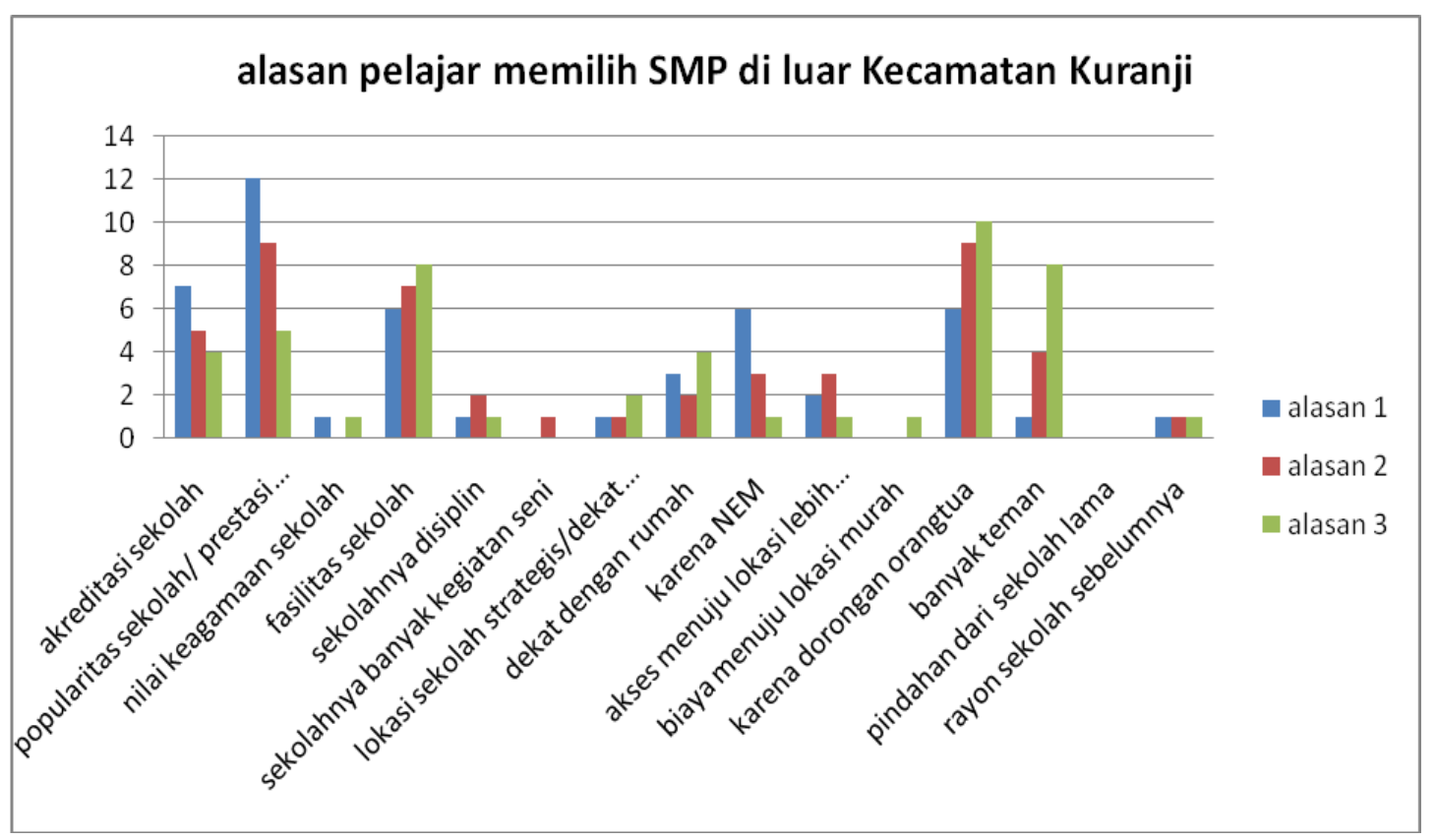

Gambar 8. Alasan Pelajar Memilih SMP di Luar Kecamatan Kuranji.

Alasan pelajar di Kecamatan Kuranji yang memilih satuan pendidikan SMP di luar kecamatan, bahwa sebagian besar memilih karena popularitas dan akreditas sekolah. Kemudian dari hasil penelitian menemukan, dorongan dari orangtua juga menjadi alasan bagi pelajar dalam memilih sekolah, artinya sebagian orangtua dari pelajar yang berdomisili di Kecamatan Kuranji menginginkan dan mengarahkan anaknya untuk mendapatkan layanan pendidikan yang lebih baik dari yang ada didomisili mereka.

Berdasarkan alasan pelajar yang memilih satuan pendidikan SMP, terlihat bahwa sebagian pelajar tidak terlalu mementingkan jarak atau lokasi dari layanan pendidikan itu sendiri. 
Padahal bila layanan pendidikannya memiliki jarak berangkat yang jauh karena waktu yang dibutuhkan dalam mencapai satuan pendidikan pasti lebih banyak, dibandingkan dengan sekolah dengan jarak yang dekat, waktu yang dibutuhkan dalam pencapaian juga tidak akan banyak. Memilih layanan pendidikan khususnya satuan pendidikan SMP dengan jarak yang jauh juga menyebabkan pelajar kelelahan sehingga dapat berpengaruh pada daya tahan belajar, seperti yang Awang, Rimang Jatmiko (2006) bahwa bila ketahanan belajar siswa rendah, hasil pembelajaran yang didapat tentu juga akan rendah, dibanding dengan sekolah dengan jarak yang dekat, daya tahan dalam belajar lebih tinggi, hasil pembelajaran yang didapat tentunya lebih tinggi.

\section{PENUTUP}

\section{Kesimpulan}

Berdasarkan hasil penelitian yang telah disampaikan, penulis menyimpulkan bahwa layanan satuan pendidikan SMP yang dipilih oleh pelajar di Kecamatan Kuranji cenderung seimbang antara pelajar yang memilih satuan pendidikan SMP yang berada di dalam Kecamatan Kuranji dengan pelajar yang memilih SMP di luar Kecamatan Kuranji, yakni 52 persen memilih di satuan pendidikan SMP di dalam Kecamatan Kuranji dan 48 persen memilih satuan maka siswa harus bangun lebih pagi agar tidak terlambat masuk sekolah, pendidikan SMP di luar Kecamatan Kuranji. Alasan pelajar dalam memilih satuan pendidikan SMP, mayoritas memilih layanan satuan pendidikan SMP yang berada di dalam karena lebih dekat dengan rumah, kemudian beralasan karena kualitas dan fasilitas sekolah. Alasan Pelajar memilih SMP di luar kecamatan sebagian besar karena popularitas sekolah dan akreditas sekolah, serta beralasan karena dorongan orang tua.

\section{Saran}

1. Bagi Pemerintah Kota Padang khususnya dinas terkait disarankan agar dilakukan upaya pemerataan kualitas layanan pendidikan khususnya SMP. Mulai dari peningkatan kualitas infrastruktur, kualitas pengajaran hingga akses untuk menuju lokasi dari layanan pendidikan tersebut. Sehingga masyarakat tidak perlu untuk memilih yang berada jauh dari domisilinya.

2. Penelitian lanjutan yang penulis sarankan yaitu terkait peranan orangtua dalam memilih layanan satuan pendidikan SMP untuk pelajar mengingat banyak pelajar yang memiliki alasan karena orangtua. Selain itu pemeetaan zonasi rayon layanan pendidikan di Kecamatan Kuranji mengingat 
dalam seleksi penerimaan siswa memakai sistem rayon sekolah.

\section{DAFTAR PUSTAKA}

Awang, Rimang Jatmiko. 2006 Analisis Pemilihan Sekolah Menengah Atas Berdasarkan Efektifitas Jarak, Sarana Angkutan Umum Dan Tingkat Unggulan Sekolah Dengan Mengunakan Sistem Informasi Geografis dan Analytical Hierarchy Process (Dengan Sampel Masyarakat Perumahan Bukit Jatisari Semarang). Skripsi. Fakultas Teknik UNNES.

BPS, 2017 Kecamatan Kuranji dalam Angka. Padang : BPS Maryati, Sri. 2009. "Faktor-Faktor yang Mempengaruhi Preferensi Masyarakat Dalam Memilih Sekolah Menengah Kejuruan Negeri (Smkn) Di Kota Semarang."Tesis tidak diterbitkan. PPs Magister Teknik Pembangunan Wilayah dan Kota-Undip.

Republik Indonesia. 2003. Undang Undang Sistem Pendidikan Nasional (UUSPN) No. 20/2003 tentang sistem pendidikan Nasional. Sekretariat Negara. Jakarta.

Republik Indonesia. 2010 Peraturan Pemerintah Nomor 17 Tahun 2010 tentang Standar Sarana dan Pengelolaan dan Penyelenggaraan Pendidikan. Sekretariat Negara. Jakarta.

Republik Indonesia. $\quad 2010$

Permendiknas Nomor 24 Tahun 2007 terkait Standar
Sarana dan Prasarana Sekolah Menengah Pertama/Madrasah Tsanawiyah (SMP/MTS) Pasal 4

Sugiyono. 2014. Metode Penelitian Kuantitatif, Kualitatif, dan Kombinasi (mixed methods). Bandung : Alfabeta. Sulipan. 2013. Layanan Pendidikan dalam Manajemen Pendidikan. https://sulipan.wordpress.com/ 2013/08/04/layananpendidikan/ diakses pada 28 Januari 2018.

Tamin, Ofyar Z. 2000. "Perencanaan dan Permodelan Transportasi”. Bandung: ITB Press

Tarigan, Robinson. Perencanaan Pembangunan Wilayah, Bumi Aksara, Jakarta, 2005. 